\title{
Health-related quality of life among patients with bipolar disorder in rural southwestern Uganda: a hospital based cross sectional study
}

\author{
Lucas Anyayo1, Scholastic Ashaba ${ }^{1 *} \mathbb{0}$, Mark Mohan Kaggwa², Samuel Maling $^{2}$ \\ and Etheldreda Nakimuli-Mpungu ${ }^{3}$
}

\begin{abstract}
Background: Bipolar disorder is a psychiatric disorder that alters mood and affects over 55 million people globally with an estimated lifetime prevalence of approximately $0.8-1.1 \%$. In Africa, the lifetime prevalence of the bipolar spectrum disorders is slightly lower at $0.1-0.6 \%$. Bipolar disorder is ranked the sixth leading cause of disability with high rates of morbidity and mortality and negatively impacts quality of life of those affected.
\end{abstract}

Methods: The aim of the study was to determine the health-related quality of life of patients with bipolar disorder attending a mental health clinic in south western Uganda. We enrolled a consecutive sample of 169 participants and evaluated their health-related quality of life using the medical outcomes health survey short form-36 (SF-36) scale. We used bivariate and multivariable logistic regression to determine associations between quality of life, sociodemographic and clinical factors setting the physical and mental component categories of quality life scale as the main outcome variables.

Results: The mean age of the participants was 37.23 (12.83) and slightly over half (54.4\%) were females. More than half (66.86\%) of the participants had poor physical component summary (mean $=45.06, \mathrm{SD}=8.44$ ) while $81 \%$ of the participants had poor mental component summary (mean $=41.95, \mathrm{SD}=8.45)$. Poor physical quality of life had a statistically significant association with history of suicidal thoughts $(\mathrm{OR}=2.75,95 \% \mathrm{Cl}=1.14-6.63, P=0.02)$, while poor mental quality of life had a statistically significant association with history of suicidal thoughts $(\mathrm{OR}=3.94, \mathrm{Cl}=1.22-$ $12.71, P=0.02)$ and history of psychotic symptoms $(\mathrm{OR}=2.46, \mathrm{Cl}=1.07-5.64, P=0.03)$.

Conclusion: The mental and physical quality of life of our participants was poor and history of suicidal thoughts and psychotic symptoms were associated with poor quality of life. There is need to address psychotic symptoms and suicidal thoughts in the management of patients with bipolar disorder to improve health related outcomes and quality of life.

Keywords: Bipolar disorder, Remission, Quality of life, Uganda

\section{Background}

Bipolar disorder (BD) is a mental illness marked by extreme shifts in mood ranging from manic to depressive states $[1,2]$. Bipolar disorder is the 6 th leading

\footnotetext{
*Correspondence: sashaba@must.ac.ug

${ }^{1}$ Lira University, Lira, Uganda

Full list of author information is available at the end of the article
}

cause of disability [3] among the non-communicable diseases and various studies estimate the prevalence to be between 1 and 2\% [4, 5]. BD affects over 54 million people worldwide [6] and is associated with high levels of morbidity and mortality [7]. BD has an estimated 4.4-10.3 (7\%) disability-adjusted life years (DALYs), making it the 7th leading cause of years of life lost (YLL) and years lived with disability (YLD) [8]. original author(s) and the source, provide a link to the Creative Commons licence, and indicate if changes were made. The images or other third party material in this article are included in the article's Creative Commons licence, unless indicated otherwise in a credit line to the material. If material is not included in the article's Creative Commons licence and your intended use is not permitted by statutory regulation or exceeds the permitted use, you will need to obtain permission directly from the copyright holder. To view a copy of this licence, visit http://creativecommons.org/licenses/by/4.0/. The Creative Commons Public Domain Dedication waiver (http://creativeco mmons.org/publicdomain/zero/1.0/) applies to the data made available in this article, unless otherwise stated in a credit line to the data. 
In Africa, the lifetime prevalence of bipolar spectrum disorders based on surveys done in Egypt and Nigeria was found to be between 0.1 and $0.6 \%$ [9]. Bipolar disorder has a chronic course characterized by frequent and recurrent episodes and this chronicity causes significant impairment in functioning [10-13] and a considerable amount of disability even after remission of symptoms [14-16]. Estimates show that $25-50 \%$ of patients with bipolar disorder attempt suicide in their lifetime while about 15-19\% commit suicide [17].

Previous studies show that the quality of life (QoL) of patients with BD is poorer compared to the general population $[18,19]$. According to the World Health Organization (WHO), quality of life is a constellation of different factors in relation to an individual and their environment including how they perceive their position in society in the context of their culture, their goals, expectations and concerns [20]. Health related quality of life comprises of different aspects of life including psychological, social and physical functioning and improved health related QoL is a good indicator of improved functioning for people with bipolar disorder and other chronic conditions [21, 22]. Presence of depressive symptoms and illicit drug use among people with bipolar disorder are associated with worsened quality of life [23, 24]. Additionally presence of psychotic symptoms during a manic episode is associated with slow recovery and high relapse rates which affect functionality $[25,26]$. People with bipolar disorder experience compromised quality of life with profound impact on different domains including education, work productivity and intimate relationships [21, 27]. Impaired quality of life has been reported to persist even when patients are in remission [28-30]. At individual level, there is a significant alteration of one's cognition, sleeping patterns, impairment in occupational functioning and disturbance in interactions with family and friends [31, 32].

BD negatively impacts health-seeking behaviors and the treatment outcomes which in turn affects the individuals' ability to function properly in society [33, 34]. Moreover, when bipolar disorder starts early in life it causes poorer global functioning, higher rates of academic failure, poor interpersonal relationships, and a high risk of suicide attempts $[35,36]$. There is a high rate of marital dysfunction in patients with $\mathrm{BD}$, including hyper and hypo-sexuality, promiscuity, lack of selfcontrol and misuse of family assets, and as a result, the rate of divorce is high among couples where a spouse has bipolar disorder [37]. Divorce and separation are more common among people with bipolar disorder than in the general population [38-40]. Furthermore, BD is highly comorbid with other medical conditions like cardiovascular diseases, HIV and other psychiatric disorders like anxiety disorders, alcohol and drug abuse [41, 42], which further affect the QoL of the affected individuals.

Several factors have been shown to contribute to the decline in functioning among people with bipolar disorder including lack of social support and poor healthseeking behaviour [29, 43]. In sub-Sahara Africa, the quality of life of patients with bipolar disorder may be worse given the numerous challenges encountered in the management and support of individuals with mental illness $[44,45]$. For example, in Uganda, with a population of approximately 40 million people [46], there are less than 30 psychiatrists, meaning that for every 1.3 million people, there is one psychiatrist. The country's economic situation and social support system, which leaves many people unemployed with minimal education, causes a further decrement in the quality of life of people with bipolar disorder [47]. Despite the negative impact that $\mathrm{BD}$ has on the social and psychological functioning of the affected individuals and their QoL, the health-related quality of life of patients with bipolar disorder in Uganda is not well established. The aim of this study was to determine the health-related quality of life and the factors associated among patients with bipolar disorder in rural southwestern Uganda.

\section{Materials and methods}

\section{Study area and study participants}

We collected data between April 15 and June 20, 2017 at the outpatient mental health clinic of Mbarara Regional Referral Hospital (MRRH) in Mbarara District MRRH is a public health facility in southwestern Uganda located $270 \mathrm{~km}$ from Kampala, the capital city. We recruited patients with a diagnosis of bipolar disorder (as confirmed by the attending clinicians) who were in remission phase, 18 years and older, both male and female, and were attending the outpatient mental health clinic at MRRH during the study period. We excluded participants who presented with active symptoms of mental illness that would interview with their cognitive ability to understand the contents of the questionnaire and the consent documents and those who were physically unwell to stand the length of the interview at the time of recruitment.

\section{Sample size estimation}

We used an online OpenEpi software, http://www.opene pi.com, based on Kelsey and colleagues [48] to calculate the sample size. Using this formula, we used a confidence level of $95 \%$, power of $80 \%$ and ratio of the sample size of the healthy population to that of participants with bipolar disorder to be one. We assumed that the percentage of the healthy population with a poor quality of life to be 20 and the percentage of patients with bipolar disorder with poor quality to be 40 . Substituting all the numbers we 
arrived at sample size of 169 participants. We recruited participants consecutively as they came to the clinic for review every week until we reached our desired sample size.

\section{Measures}

We used a locally generated questionnaire to collect social demographic and clinical information of the participants including age, sex, marital status, level of education and source of income. Information on clinical factors included age at onset of the illness, number of episodes in the past year, number of hospital admissions in the past year and presence of suicidal thoughts and psychotic symptoms in the last acute episode. We assessed health related quality of life using the medical outcomes health survey short form-36 (SF-36) scale [49].The SF-36 is a 36-item, self-administered measure of QoL that was developed to examine the impact of disease on perceived well-being. It consists of eight subscales that measure different areas of functioning including: (1) physical functioning; (2) role disruption because of physical difficulties (role disruption-physical); (3) role disruption caused by emotional difficulties (role disruption-emotional); (4) social functioning; (5) mental health; (6) vitality; (7) general health; and (8) bodily pain. Each item is scored on 6 point Likert-type scale. Four of these domains are considered to relate to mental health, namely: (1) role limitations due to personal or emotional problems ("roleemotional"); (2) emotional wellbeing, (3) social functioning and (4) energy and fatigue. Together, these four scores form a single mental component scale, while the other four sub-scales (physical functioning, role disruption because of physical difficulties, vitality and general health) aggregate into a physical component scale. Physical (PCS) and mental (MCS) component summary measures were calculated by weighting each SF-36 item using a norm-based scoring method given in the guidelines [50, 51]. Since Uganda does not have a population norm, the norm used was that of the Tanzania population while adapting the SF 36 [52]. Pre-coded numeric values from the questionnaire, on a Likert type scale, were recorded according to the scoring key given and items were then scored in such a way that the higher the score, the better the health state [51]. Each item was scored on a 0-100 range with 0 being the lowest and 100 the highest possible score. The summary statistics (i.e. Physical and Mental Summary Scores, PCS and MCS respectively) were calculated by averaging the different normalized scales. Finally, the summary scores were then standardized to give a mean of 50 and a standard deviation of 10 by multiplying the PCS and MCS scores by 10 and adding 50 to the product. Higher scores indicate better health on each of the sub-scales [22, 51, 53].
The tool has been used in Uganda and other East Africa countries with good reliability measures [52, $54,55]$. The tool was translated into Runyankore, (the local language in southwestern Uganda), using recommended guidelines (Maxwell, 1996; Peters and Passchier, 2006; Gudmundsson, 2009). We adjusted the SF-36 to fit the context of the study setting. Several phrases and actions in the physical activity section (i.e. climbing a flight of stairs, playing golf, walking one block, walking several blocks and pushing a vacuum cleaner) were replaced with appropriate activities that suit the local context. For example, climbing a flight of stairs was changed to climbing a hill, pushing a vacuum cleaner changed to lifting a 20-L can of water. The adaptations were made following the Swahili version of the SF-36 that was adapted for use in Tanzania [52].

\section{Ethics}

The study was approved by the Research Ethics Committee (REC) of Mbarara University of Science and Technology (\#19/11-16) and Uganda National Council for Science and Technology (\# SS4309). All study participants provided written informed consent and received no facilitation for participation in the study. The data collected were confidential and anonymous with no information linking the study participants to the data. Participants who got severe distress during the interview were referred to a counsellor for appropriate care.

\section{Data analysis}

We summarized categorical data as frequencies and percentages while continuous data were summarized as means and standard deviation (SD). We carried out a bivariate analysis using logistic regression for all the predictor variables and the outcome variables. The outcome variables were the physical and mental component categories of the quality of life scale.

Quality of life summary scores (i.e. physical (PCS) and mental (MCS) summary Scores) were calculated by averaging the different normalized scales from the relevant subscales. Values below 50 indicated poor health-related quality of life and those above 50 indicated a good quality of life $[50,51]$. We recorded unadjusted odds ratios, $p$ values and confidence intervals and summarized findings in tables. We controlled for sex and age to determine adjusted odds, at $95 \%$ confidence intervals and statistical significance was determined at a $p$ value of $<0.05$. We then ran a multivariable logistic regression analysis with all the independent variables by including in the model all factors that had a $p$ value of $\leq 0.3$ at bivariate analysis. 


\section{Results}

Of the 169 participants enrolled 92 (54.44\%) were females and the mean age of the participants was 37.2 (SD 12.8) years. The average age of onset of mental illness was 24.68 (SD 8.87) years. Overall the quality of life was poor with $113(66.86 \%)$ of the participants having a poor physical component summary of the quality of life, while 137 (81.07\%) reporting a poor mental component summary of the quality of life (Table 1 ).

The overall mean subscale scores of the study sample were below 82 with the highest attained value being 81 which was in the category of bodily pain. Most of the parameters scored between the 50th and 60th percentiles. Table 2 shows the mean and standard deviation of the sub-scales, physical component summary and mental component summary of the entire sample aggregated by sex. The standardized physical component score and the mental component summary were all below average 45.06 (SD 8.44) and 41.95 (SD 8.45) respectively. There were minor differences between the sub-scale means between men and women. Women scored less than males in mental health, social functioning, vitality, bodily pain and general health hence the lower score for the overall mental component summary.

On bivariate analysis we run sociodemographic and clinical factors against mental and physical quality of life as our outcome variables. History of suicidal thoughts and psychosis were significantly associated with both poor physical and mental quality of life (Table 3 ).

At multivariable logistic regression analysis, poor physical quality of life had a statistically significant association with suicidal thoughts [AOR 2.75 (1.14-6.63), $P=0.02$ ], while poor mental quality of life had a statistically significant association with history of psychosis [AOR 3.94 $(1.22-12.71) P=0.02$ ] and suicidal thoughts [AOR2.46 (1.07-5.64), $P=0.03$ ] (Table 4).

\section{Discussion}

Results from our study show that bipolar disorder is associated with impairment in the health-related quality of life with impairment in both physical and mental aspects of life. This finding is consistent with other studies in both low and high-income countries in which bipolar disorder was found to impair the quality of life of patients with the disorder $[29,56,57]$. In the study by Kebede et al. presence of depressive symptoms in the most recent episode was associated with poorer quality of life [56]. Sixty-seven percent (67\%) of the participants in our study had a poor physical quality of life, whereas $81 \%$ had a poor mental quality of life which is in agreement with previous studies that the physical and mental components of life tend to be lower among people with
Table 1 Sociodemographic characteristics of the participants $(\mathrm{N}=169)$

\begin{tabular}{|c|c|}
\hline Characteristic & $\begin{array}{l}\text { Mean (SD) OR } \\
\mathrm{n}(\%)\end{array}$ \\
\hline Age & $37.23(12.83)$ \\
\hline The average number of episodes in a year & $01(2.35)$ \\
\hline Time since the last episode (months) & $15.55(27.65)$ \\
\hline Age at onset of illness & $24.6815 .55(8.8727 .65)$ \\
\hline Number of admissions in the previous year & $01.02(1.95)$ \\
\hline \multicolumn{2}{|l|}{ Sex } \\
\hline Female & $92(54.44)$ \\
\hline Male & $77(45.56)$ \\
\hline \multicolumn{2}{|l|}{ Religion } \\
\hline Catholic & $72(42.60)$ \\
\hline Protestant & $66(39.05)$ \\
\hline Muslim & $12(7.10)$ \\
\hline Others & $19(11.24)$ \\
\hline \multicolumn{2}{|l|}{ Employment status } \\
\hline Subsistence farmer & $59(34.91)$ \\
\hline Business & $39(23.08)$ \\
\hline Civil servant & $22(13.02)$ \\
\hline Not employed & $42(24.85)$ \\
\hline Others & $7(4.14)$ \\
\hline \multicolumn{2}{|l|}{ Area of residence } \\
\hline Urban & $47(27.81)$ \\
\hline Rural & $122(72.19)$ \\
\hline \multicolumn{2}{|l|}{ Level of education } \\
\hline No formal education & $13(7.69)$ \\
\hline Some primary & $29(17.16)$ \\
\hline Completed primary & $17(10.06)$ \\
\hline Some secondary & $46(27.22)$ \\
\hline Completed secondary & $23(13.61)$ \\
\hline Tertiary & $41(24.26)$ \\
\hline \multicolumn{2}{|l|}{ Marital status } \\
\hline Single & $66(39.05)$ \\
\hline Married & $63(37.28)$ \\
\hline Separated & $30(17.75)$ \\
\hline Widowed & $10(5.92)$ \\
\hline \multicolumn{2}{|l|}{ HIV status } \\
\hline Negative & $128(75.74)$ \\
\hline Positive & $19(11.24)$ \\
\hline Unknown & $22(13.02)$ \\
\hline \multicolumn{2}{|l|}{ History of suicide ideation } \\
\hline Yes & $61(36.09)$ \\
\hline No & $108(63.91)$ \\
\hline \multicolumn{2}{|l|}{ History of suicide attempt } \\
\hline Yes & $44(26.04)$ \\
\hline No & $125(73.96)$ \\
\hline \multicolumn{2}{|l|}{ History of psychotic symptoms } \\
\hline Yes & $89(52.66)$ \\
\hline No & $80(47.34)$ \\
\hline
\end{tabular}


Table 1 (continued)

\begin{tabular}{ll}
\hline Characteristic & $\begin{array}{l}\text { Mean (SD) OR } \\
\mathrm{n}(\%)\end{array}$ \\
\hline $\begin{array}{l}\text { Physical quality of life } \\
\text { Poor } \\
\text { Good } \\
\text { Mental quality of life } \\
\text { Poor }\end{array}$ & $113(66.86)$ \\
Good & $56(33.13)$ \\
\hline
\end{tabular}

bipolar disorder compared to the general population [58]. However, the mental quality of life was more affected compared to the physical aspect among our sample and this may be explained by the fact that bipolar disorder affects different psychological domains including selfesteem, thinking, memory, and concentration compared to the physical domains $[59,60]$. Additionally, the worry about living with a chronic recurring illness may contribute to worsened mental quality of life [60].

Our study found that history of having had suicidal thoughts and psychotic symptoms in the most recent episode were associated with poor physical and mental quality of life. These findings are in agreement with previous studies indicating that suicidal ideations are associated with poor quality of life $[19,61]$. The association between suicidal ideations and poor quality of life among people with bipolar disorder has been linked to challenges of life satisfaction among people with mental health problems [62]. It has also been documented that on average people with bipolar disorder spend more time depressed than manic which may also explain the link between suicidal ideations and worsened quality of life [63]. The association between psychotic symptoms and quality of life has been reported in previous studies [64-66]. The association between psychotic symptoms and poor quality of life
Table 3 Bivariate analysis of the factors and poor physical quality of life (after adjusting for age and sex)

\begin{tabular}{lll}
\hline Characteristic & $\begin{array}{l}\text { Adjusted } \mathrm{OR}, 95 \% \mathrm{Cl} \\
P \text { value } \\
\text { Mental quality of life }\end{array}$ & $\begin{array}{l}\text { Adjusted OR, 95\% Cl } \\
P \text { value } \\
\text { Physical quality of life }\end{array}$ \\
\hline Residence (rural) & $0.98(0.41-2.31), 0.96$ & $0.57(0.28-1.14), 0.11$ \\
Employment status & $0.87(0.64-1.18), 0.38$ & $1.11(0.85-1.44), 0.46$ \\
Level of education & $0.85(0.67-1.09), 0.20$ & $1.00(0.82-1.23), 0.97$ \\
Marital status & $1.37(0.82-2.29), 0.23$ & $0.93(0.61-1.42), 0.74$ \\
HIV status (positive) & $0.77(0.42-1.41), 0.39$ & $1.14(0.72-1.80), 0.56$ \\
Age at onset of illness & $1.01(0.96-1.07), 0.59$ & $1.14(0.72-1.80), 0.56$ \\
Number of episodes/ & $0.80(0.59-1.08), 0.14$ & $0.89(0.75-1.07), 0.24$ \\
$\quad$ year & & \\
Time since last episode & $0.99(0.98-1.01), 0.54$ & $1.01(0.99-1.02), 0.147$ \\
Admissions in the last & $0.95(0.76-1.19), 0.65$ & $0.86(0.69-1.06), 0.17$ \\
$\quad$ year & & \\
Suicidal thoughts & $2.98(1.13-7.81), 0.03$ & $1.99(0.97-4.08), 0.06$ \\
Suicidal attempt & $1.05(0.42-2.61), 0.91$ & $0.74(0.36-1.54), 0.42$ \\
Psychotic symptoms & $2.56(1.13-5.77), 0.02$ & $1.819(0.958-3.4566)$, \\
& & 0.026
\end{tabular}

among people with bipolar disorder may be partly due to delayed response to treatment of the psychotic symptoms which affects functional recovery [67]. In addition, psychosis during manic episodes has been associated with longer periods of illness, higher relapse rates and increased symptom severity [25, 26, 65]. Moreover, the presence of psychotic symptoms during manic episodes are considered as a sign of poor prognosis [64].

Our study did not register any significant difference between the physical component summary scores between men and women. This is inconsistent with findings from a study by De la Cruz in which women had a lower physical summary score than men [68]. However in the study by de la Cruz the reported lower

Table 2 SF-36 subscale mean scores stratified by sex

\begin{tabular}{lccc}
\hline Scales & $\begin{array}{l}\text { Total sample } \\
\text { Mean (SD) }\end{array}$ & $\begin{array}{l}\text { Male } \\
\text { Mean (SD) }\end{array}$ & $\begin{array}{c}\text { Female } \\
\text { Mean (SD) }\end{array}$ \\
\hline Physical function & $79.47(21.75)$ & $79.16(24.41)$ & $79.73(19.39)$ \\
Physical role limitation & $56.36(45.48)$ & $53.57(47.59)$ & $58.70(43.76)$ \\
Emotional role limitation & $55.23(46.30)$ & $54.98(46.44)$ & $55.43(46.43)$ \\
Vitality & $59.97(19.51)$ & $61.56(19.66)$ & $58.64(19.39)$ \\
Mental health & $69.18(18.74)$ & $70.81(17.83)$ & $77.83(19.47)$ \\
Social function & $73.45(24.18)$ & $74.19(24.02)$ & $72.83(24.42)$ \\
Bodily pain & $81.05(25.70)$ & $83.05(21.71)$ & $79.38(28.63)$ \\
General Health & $61.04(21.32)$ & $62.08(20.09)$ & $60.16(22.37)$ \\
Summary score & & & $45.13(8.36)$ \\
Physical component summary (PCS & $45.06(8.44)$ & $42.45(8.53)$ & $45.01(8.55)$ \\
Mental component summary (MCSO & $41.95(8.45)$ & $41.53(8.40)$ \\
\hline
\end{tabular}


Table 4 Multivariable model depicting the poor quality of life (mental and physical quality of life)

\begin{tabular}{lll}
\hline Characteristic & $\begin{array}{l}\text { Adjusted OR, 95\% Cl } \\
P \text { value } \\
\text { Poor mental quality of life }\end{array}$ & $\begin{array}{l}\text { Adjusted OR, 95\% } \mathrm{Cl} \\
P \text { value } \\
\text { Poor physical quality of life }\end{array}$ \\
\hline Time since last episode & $0.99(0.97-1.01), 0.41$ & $1.01(0.99-1.02), 0.2174$ \\
Average number of episode in a year & $0.79(0.58-1.09), 0.15$ & $0.89(0.75-1.08) 0.25$ \\
Suicidal thoughts & $3.94(1.22-12.71), 0.02$ & $2.75(1.14-6.63), 0.02$ \\
Suicide attempts & $0.50(0.16-1.53), 0.23$ & $1.64(0.84-0.83) 0.07$ \\
Psychotic symptoms & $2.46(1.07-5.64), 0.03$ & $\mathrm{~N} / \mathrm{A} 1.89(0.98-3.66) 0.06$ \\
Admissions in the previous year & - & $0.84(0.67-1.06), 0.12$ \\
\hline
\end{tabular}

physical quality of life among women compared to men in their sample was linked to high risk of medical comorbidities among women compared to men [68]. In our study we did not assess for medical comorbidities and this may explain the difference in our findings. However, the mental component summary in our study was lower among women than men. The low mental component summary among women in our study may be linked to the overwhelming emotional and environmental stigma imparted on women in the Ugandan setting compared to men [69]. The lower mental component summary (MCS) in regards to the gender is in agreement with what has been reported in previous studies [68]. Female sex has been linked to poorer quality of life among patients with bipolar disorder due to the fact that women with bipolar disorder tend to suffer more depressive episodes compared to men yet depressive symptoms are associated with more impairment in the quality of life among patients with bipolar disorder $[23,24,70]$,

Contrary to what has been reported in some studies [71-73], we did not find statistically significant associations between number of episodes or number of admissions in the past year with quality of life. However, our findings are in agreement with findings by Sierra et al. [29] who found that duration of mental illness and number of previous episodes did not predict quality among patients with bipolar disorder. Studies that have found the relationship between number of episodes and impaired quality of life have pointed out that depressive episodes tend to have a greater impact on quality of life than the manic episodes [13]. In addition, studies that have found significant associations between number of episodes or number of admissions with quality of life among patients with bipolar disorder show a higher number of manic and depressive episodes and several admissions in the past [73]. In our study our participants had on average one episode and one admission in the previous year which may explain why number of episodes and admissions in the previous year did not predict quality of life.
Our study had some limitations. First, we collected data from participants who were receiving regular mental health services from a well-structured mental health clinic and hence their views may not be a true representation of all the patients with $\mathrm{BD}$ in rural southwestern Uganda. Secondly, we were asking participants about events that took place in the past and this could have resulted in recall bias hence inconsistent responses as participants reported past events. Third, we did not use standard scales to confirm the diagnosis of the participants and as such we could have enrolled some participants who did not have a true diagnosis of bipolar disorder. However, since the clinic is run by qualified psychiatrists we are confident that the findings reflected in this study in relation to quality of life represent those of patients with bipolar disorder in our setting.

\section{Conclusions}

Our findings indicate that patients with bipolar disorder have a poor quality of life and that having had suicidal thoughts and psychosis predict poor quality of life among patients with bipolar disorder. Health care providers must bear in mind the impact bipolar disorder has on quality of life of those who suffer this condition so that appropriate measures are put in place to improve health outcomes of the patients. There is need to pay close attention to the psychotic symptoms and suicidal thoughts during the management of patients with bipolar disorder so that these can be controlled in addition to mood stabilization to improve physical and mental health outcomes. Additionally, the management of patients with bipolar disorder should focus on both the physical and mental health domains to improve quality of life.

\section{Abbreviations}

BD: Bipolar disorder; YLL: Years of life lost; YLD: Years lived with disability; QoL: Quality of life; MRRH: Mbarara Regional Referral Hospital; REC: Research Ethics Committee; PCS: Physical comment summary; MCS: Mental component summary; SF-36: Health survey short form-36. 


\section{Acknowledgements}

We thank the participants who took their time to participate in this study and we also acknowledge the contributions of our research assistants to data collection and logistical support during the study period.

\section{Authors' contributions}

LA designed the study, participated in data collection, data entry, data cleaning, statistical analyses, interpretation of the data and revising the manuscript, SA participated in the design of the study, statistical analyses data interpretation and drafted and continually revised the manuscript. MHK SM participated in data interpretation and revising of the manuscript. ENM provided comments on data interpretation participated in manuscript revision. All authors read and approved the final manuscript.

\section{Funding}

The study was funded by the PAIKO foundation in conjunction with Mbarara University of Science and Technology. The funders had no role in the design of the study, data collection, data analysis and interpretation.

\section{Availability of data materials}

The dataset (s) supporting the conclusions of this article is (are) included within the article (and its additional file(s)).

\section{Declarations}

\section{Ethics approval and consent to participate}

The study was approved by the Research Ethics Committee (REC) of Mbarara University of Science and Technology (\#19/11-16) and Uganda National Council for Science and Technology (\# SS4309. All participants provided written informed consent before enrollment in the study and received no facilitation for participation in the study.

\section{Consent for publication}

The data collected were confidential and anonymous with no information linking the study participants to the data in this manuscript.

\section{Competing interests}

The authors have no conflict of interest to declare.

\section{Author details}

${ }^{1}$ Lira University, Lira, Uganda. ${ }^{2}$ Mbarara University of Science and Technology, Mbarara, Uganda. ${ }^{3}$ Makerere University College of Health Sciences, Kampala, Uganda.

Received: 19 August 2020 Accepted: 2 March 2021

Published online: 10 March 2021

\section{References}

1. Müller-Oerlinghausen B, Berghöfer A, Bauer M. Bipolar disorder. The Lancet. 2002;359(9302):241-7.

2. Grunze H. Bipolar disorder. In: Neurobiology of brain disorders. Elsevier, 2015. p. 655-3.

3. Eroğlu MZ, Karakuş G, Tamam L. Bipolar disorder and suicide. Dusunen Adam. 2013;26:139-47.

4. Bauer M, Pfennig A. Epidemiology of bipolar disorders. Epilepsia. 2005:46:8-13.

5. Merikangas KR, Akiskal HS, Angst J, Greenberg PE, Hirschfeld RM, Petukhova M, Kessler RC. Lifetime and 12-month prevalence of bipolar spectrum disorder in the National Comorbidity Survey replication. Arch Gen Psychiatry. 2007;64(5):543-52.

6. Vos T, Barber RM, Bell B, Bertozzi-Villa A, Biryukov S, Bolliger I, Charlson F, Davis A, Degenhardt L, Dicker D. Global, regional, and national incidence, prevalence, and years lived with disability for 301 acute and chronic diseases and injuries in 188 countries, 1990-2013: a systematic analysis for the Global Burden of Disease Study 2013. The Lancet. 2015;386(9995):743-800.

7. Ferrari AJ, Baxter AJ, Whiteford HA. A systematic review of the global distribution and availability of prevalence data for bipolar disorder. J Affect Disord. 2011;134(1-3):1-13.
8. Whiteford HA, Degenhardt L, Rehm J, Baxter AJ, Ferrari AJ, Erskine HE, Charlson FJ, Norman RE, Flaxman AD, Johns N. Global burden of disease attributable to mental and substance use disorders: findings from the Global Burden of Disease Study 2010. The lancet. 2013;382(9904):1575-86.

9. Esan O, Esan A. Epidemiology and burden of bipolar disorders in Africa: a systematic review of available data from Africa. Eur Psychiatry. 2015;30:546.

10. Zarate CA, Tohen M, Land M, Cavanagh S. Functional impairment and cognition in bipolar disorder. Psychiatr Q. 2000;71(4):309-29.

11. Calabrese JR, Hirschfeld R, Reed M, Davies MA, Frye MA, Keck Jr PE, Lewis L, McElroy SL, McNulty JP, Wagner KD. Impact of bipolar disorder on a US community sample. J Clin Psychiatry. 2003.

12. Dunner DL. Clinical consequences of under-recognized bipolar spectrum disorder. Bipolar Disord. 2003;5(6):456-63.

13. MacQueen GM, Young LT, Robb JC, Marriott M, Cooke RG, Joffe RT. Effect of number of episodes on wellbeing and functioning of patients with bipolar disorder. Acta Psychiatr Scand. 2000;101(5):374-81.

14. Bonnín C, Martínez-Arán A, Torrent C, Pacchiarotti l, Rosa A, Franco C, Murru A, Sanchez-Moreno J, Vieta E. Clinical and neurocognitive predictors of functional outcome in bipolar euthymic patients: a long-term, follow-up study. J Affect Disord. 2010;121(1-2):156-60.

15. Huxley N, Baldessarini RJ. Disability and its treatment in bipolar disorder patients. Bipolar Disord. 2007;9(1-2):183-96.

16. Sanchez-Moreno J, Martinez-Aran A, Tabarés-Seisdedos R, Torrent C, Vieta E, Ayuso-Mateos J. Functioning and disability in bipolar disorder: an extensive review. Psychother Psychosom. 2009;78(5):285-97.

17. Pompili M, Gonda X, Serafini G, Innamorati M, Sher L, Amore M, Rihmer Z, Girardi P. Epidemiology of suicide in bipolar disorders: a systematic review of the literature. Bipolar Disord. 2013;15(5):457-90.

18. Maglinte GA, Hays RD, Kaplan RM. US general population norms for telephone administration of the SF-36v2. J Clin Epidemiol. 2012;65(5):497-502.

19. de Abreu LN, Nery FG, Harkavy-Friedman JM, de Almeida KM, Gomes BC, Oquendo MA, Lafer B. Suicide attempts are associated with worse quality of life in patients with bipolar disorder type I. Compr Psychiatry. 2012;53(2):125-9.

20. Whogol Group. The World Health Organization quality of life assessment (WHOQOL): position paper from the World Health Organization. Soc Sci Med. 1995;41(10):1403-9.

21. IsHak WW, Brown K, Aye SS, Kahloon M, Mobaraki S, Hanna R. Healthrelated quality of life in bipolar disorder. Bipolar Disord. 2012;14(1):6-18.

22. Hays RD, Hahn H, Marshall G. Use of the SF-36 and other health-related quality of life measures to assess persons with disabilities. Arch Phys Med Rehabil. 2002;83:S4-9.

23. Miller CJ, Abraham KM, Bajor LA, Lai Z, Kim HM, Nord KM, Goodrich DE, Bauer MS, Kilbourne AM. Quality of life among patients with bipolar disorder in primary care versus community mental health settings. J Affect Disord. 2013;146(1):100-5.

24. Kilbourne AM, Perron BE, Mezuk B, Welsh D, Ilgen M, Bauer MS. Cooccurring conditions and health-related quality of life in patients with bipolar disorder. Psychosom Med. 2009;71(8):894-900.

25. Coryell W, Leon AC, Turvey C, Akiskal HS, Mueller T, Endicott J. The significance of psychotic features in manic episodes: a report from the $\mathrm{NIMH}$ collaborative study. J Affect Disord. 2001;67(1-3):79-88.

26. Canuso CM, Bossie CA, Zhu Y, Youssef E, Dunner DL. Psychotic symptoms in patients with bipolar mania. J Affect Disord. 2008;111(2-3):164-9.

27. Michalak EE, Yatham LN, Kolesar S, Lam RW. Bipolar disorder and quality of life: a patient-centered perspective. Qual Life Res. 2006;15(1):25-37.

28. Michalak EE, Yatham LN, Lam RW. Quality of life in bipolar disorder: a review of the literature. Health Qual Life Outcomes. 2005;3(1):72.

29. Sierra P, Livianos L, Rojo L. Quality of life for patients with bipolar disorder: relationship with clinical and demographic variables. Bipolar Disord. 2005;7(2):159-65.

30. Gazalle FK, Frey BN, Hallal PC, Andreazza AC, Cunha ÂBM, Santin A, Kapczinski F. Mismatch between self-reported quality of life and functional assessment in acute mania: a matter of unawareness of illness? J Affect Disord. 2007;103(1-3):247-52.

31. Abraham KM, Miller CJ, Birgenheir DG, Lai Z, Kilbourne AM. Self-efficacy and quality of life among people with bipolar disorder. J Nerv Ment Dis. 2014;202(8):583. 
32. Awad AG, Rajagopalan K, Bolge SC, McDonnell DD. Quality of life among bipolar disorder patients misdiagnosed with major depressive disorder. Primary Care Companion J Clin Psychiatry. 2007;9(3):195.

33. Kupfer DJ, Frank E, Grochocinski VJ, Cluss PA, Houck PR, Stapf DA. Demographic and clinical characteristics of individuals in a bipolar disorder case registry. J Clin Psychiatry. 2002;63(2):120-5.

34. Hirschfeld R, Lewis L, Vornik LA. Perceptions and impact of bipolar disorder: How far have we really come? Results of the national depressive and manic-depressive association 2000 survey of individuals with bipolar disorder. J Clin Psychiatry, 2003.

35. Ernst CL, Goldberg JF. Clinical features related to age at onset in bipolar disorder. J Affect Disord. 2004;82(1):21-7.

36. Leboyer M, Henry C, Paillere-Martinot ML, Bellivier F. Age at onset in bipolar affective disorders: a review. Bipolar Disord. 2005;7(2):111-8.

37. Inanli I, Eren I, Etli T, Arslan M, Er M, Caliskan AM, Yilmaz YE. Marriage stories of individuals with bipolar disorder in relation with the illness. Klinik Psikofarmakoloji Bulteni. 2015;25:S144.

38. Suppes T, Leverich GS, Keck PE, Nolen WA, Denicoff KD, Altshuler LL, McElroy SL, Rush AJ, Kupka R, Frye MA. The Stanley Foundation bipolar treatment outcome network, II: demographics and illness characteristics of the first 261 patients. J Affect Disord. 2001; 67(1-3): 45-59.

39. Kogan JN, Otto MW, Bauer MS, Dennehy EB, Miklowitz DJ, Zhang HW, Ketter T, Rudorfer MV, Wisniewski SR, Thase ME. Demographic and diagnostic characteristics of the first 1000 patients enrolled in the Systematic Treatment Enhancement Program for Bipolar Disorder (STEP-BD). Bipolar Disord. 2004;6(6):460-9.

40. Granek L, Danan D, Bersudsky Y, Osher Y. Living with bipolar disorder: the impact on patients, spouses, and their marital relationship. Bipolar Disord. 2016;18(2):192-9.

41. Regier DA, Farmer ME, Rae DS, Locke BZ, Keith SJ, Judd LL, Goodwin FK. Comorbidity of mental disorders with alcohol and other drug abuse: results from the Epidemiologic Catchment Area (ECA) study. JAMA. 1990;264(19):2511-8.

42. McElroy SL, Altshuler LL, Suppes T, Keck PE Jr, Frye MA, Denicoff KD, Nolen WA, Kupka RW, Leverich GS, Rochussen JR. Axis I psychiatric comorbidity and its relationship to historical illness variables in 288 patients with bipolar disorder. Am J Psychiatry. 2001;158(3):420-6.

43. Sylvia LG, Montana RE, Deckersbach T, Thase ME, Tohen M, Reilly-Harrington N, Mclnnis MG, Kocsis JH, Bowden C, Calabrese J. Poor quality of life and functioning in bipolar disorder. Int J Bipolar Disord. 2017:5(1):1-8.

44. Addo R, Agyemang SA, Tozan Y, Nonvignon J. Economic burden of caregiving for persons with severe mental illness in sub-Saharan Africa: a systematic review. PLOS ONE. 2018, 13(8), e0199830.

45. Patel V, Wesseley S. Culture and common mental disorders in Sub-Saharan Africa. Psychology Press; 1998.

46. Uganda Bureau of Statistics. The population of the regions of the Republic of Uganda and all cities and towns of more than 15,000 inhabitants. In: Statistcial Abstract Kampala; 2014. p. 306.

47. Wilson F. Poverty and the quality of life: lessons from South African Research. In: Quality of life and the millennium challenge. Springer; 2009. p. 19-25.

48. Kelsey WE, Kelsey JL, Whittemore AS, Evans AS, Thompson WD. Methods in observational epidemiology. In: Monographs in epidemiology; 1996, vol 26.

49. Stewart AL, Hays RD, Ware JE. The MOS short-form general health survey: reliability and validity in a patient population. Med Care 1988;26(7):724-35.

50. Ware JE, Kosinski M, Keller S. SF-36 physical and mental health summary scales: a user's manual: Health Assessment La; 1994.

51. Ware JE. Scoring the SF-36. SF-36 Health Survey: Manual and Interpretation Guide; 1993.

52. Wagner A, Wyss K, Gandek B, Kilima P, Lorenz S, Whiting D. A Kiswahili version of the SF-36 Health Survey for use in Tanzania: translation and tests of scaling assumptions. Qual Life Res. 1999:8(1-2):101-10.

53. Stewart AL, Ware JE. Measuring functioning and well-being: the medical outcomes study approach. Duke University Press; 1992

54. Kisaka SM, Rutebemberwa E, Kasasa S, Ocen F, Nankya-Mutyoba J. Does health-related quality of life among adults with pulmonary tuberculosis improve across the treatment period? A hospital-based cross sectional study in Mbale Region, Eastern Uganda. BMC Res Notes. 2016;9(1):467.

55. Wanyonyi S, Stones W, Sequeira E. Utility of the short form (SF)-36 health related quality of life questionnaire as a measure of outcome among contraceptive users. J Obstet Gynaecol East Cent Afr. 2011;23(1):14-8.

56. Kebede D, Alem A, Shibire T, Deyassa N, Negash A, Beyero T, Medhin G, Fekadu A. Symptomatic and functional outcome of bipolar disorder in Butajira Ethiopia. J Affect Disord. 2006;90(2-3):239-49.

57. Saarni SI, Viertiö S, Perälä J, Koskinen S, Lönnqvist J, Suvisaari J. Quality of life of people with schizophrenia, bipolar disorder and other psychotic disorders. Br J Psychiatry. 2010;197(5):386-94.

58. Gutiérrez-Rojas L, Gurpegui M, Ayuso-Mateos JL, Gutiérrez-Ariza JA, RuizVeguilla M, Jurado D. Quality of life in bipolar disorder patients: a comparison with a general population sample. Bipolar Disord. 2008;10(5):625-34.

59. Studart P, Galvão-de Almeida A, Bezerra-Filho S, Caribé A, Afonso NR, Daltro C, Miranda-Scippa Â. Is history of suicidal behavior related to social support and quality of life in outpatients with bipolar I disorder? Psychiatry Res. 2016;246:796-802.

60. Berlim MT, Pargendler J, Caldieraro MA, Almeida EA, Fleck MP, Joiner TE. Quality of life in unipolar and bipolar depression: Are there significant differences? J Nerv Ment Dis. 2004;192(11):792-5.

61. Berlim MT, Mattevi BS, Pavanello DP, Caldieraro MA, Fleck MP. Suicidal ideation and quality of life among adult Brazilian outpatients with depressive disorders. J Nerv Ment Dis. 2003;191(3):193-7.

62. Koivumaa-Honkanen H, Honkanen R, Viinamaeki H, Heikkilae K, Kaprio J, Koskenvuo M. Life satisfaction and suicide: a 20-year follow-up study. Am J Psychiatry. 2001;158(3):433-9.

63. Judd LL, Akiskal HS, Schettler PJ, Endicott J, Maser J, Solomon DA, Leon AC, Rice JA, Keller MB. The long-term natural history of the weekly symptomatic status of bipolar I disorder. Arch Gen Psychiatry. 2002;59(6):530-7.

64. Tohen M, Waternaux CM, Tsuang MT. Outcome in mania: a 4-year prospective follow-up of 75 patients utilizing survival analysis. Arch Gen Psychiatry. 1990;47(12):1106-11.

65. Nehme E, Obeid S, Hallit S, Haddad C, Salame W, Tahan F. Impact of psychosis in bipolar disorder during manic episodes. Int J Neurosci. 2018;128(12):1128-34.

66. Bora E, Vahip S, Akdeniz F, Gonul AS, Eryavuz A, Ogut M, Alkan M. The effect of previous psychotic mood episodes on cognitive impairment in euthymic bipolar patients. Bipolar Disord. 2007;9(5):468-77.

67. Conus P, Cotton S, Abdel-Baki A, Lambert M, Berk M, McGorry PD. Symptomatic and functional outcome 12 months after a first episode of psychotic mania: barriers to recovery in a catchment area sample. Bipolar Disord. 2006;8(3):221-31.

68. de la Cruz MSD, Lai Z, Goodrich DE, Kilbourne AM. Gender differences in health-related quality of life in patients with bipolar disorder. Arch Womens Ment Health. 2013;16(4):317-23.

69. Kaaya S, Eustache E, Lapidos-Salaiz I, Musisi S, Psaros C, Wissow L. Grand challenges: improving HIV treatment outcomes by integrating interventions for co-morbid mental illness. PLoS Med. 2013;10(5):e1001447.

70. Robb JC, Young LT, Cooke RG, Joffe RT. Gender differences in patients with bipolar disorder influence outcome in the medical outcomes survey (SF-20) subscale scores. J Affect Disord. 1998;49(3):189-93.

71. Sclare P, Creed F. Life events and the onset of mania. Br J Psychiatry. 1990;156(4):508-14.

72. Bidzińska EJ. Stress factors in affective diseases. Br J Psychiatry. 1984;144(2):161-6.

73. Rosa AR, Reinares M, Franco C, Comes M, Torrent C, Sánchez-Moreno J, Martínez-Arán A, Salamero M, Kapczinski F, Vieta E. Clinical predictors of functional outcome of bipolar patients in remission. Bipolar Disord. 2009;11(4):401-9.

\section{Publisher's Note}

Springer Nature remains neutral with regard to jurisdictional claims in published maps and institutional affiliations. 